\title{
Mechanical and Fractographical Characterization of Extruded AI-Mg-Si-Zr Alloys
}

\author{
Fulya Kahrıman ${ }^{1, *}$, Muzaffer Zeren ${ }^{1}$ \\ ${ }^{1}$ Kocaeli University, Department of Metallurgical and Materials Engineering, 41380 Kocaeli, Turkey
}

\begin{abstract}
In this study, the chemical composition of $\mathrm{Al}-0.8 \mathrm{Mg}-0.8 \mathrm{Si}$ alloys was modified with the addition of 0.1 and $0.2 \mathrm{wt} .-\% \mathrm{Zr}$. The billets were manufactured by direct chill casting method, homogenized at $560{ }^{\circ} \mathrm{C}$ for $6 \mathrm{~h}$ and then extruded in order to obtain profiles having hollow and circular sections. Recrystallization layer (shell) became narrower due to the addition of $\mathrm{Zr}$. This was attributed to the formation of very fine precipitates $\left(\mathrm{Al}_{3} \mathrm{Zr}\right)$ within the matrix. The mechanical properties showed that both yield and tensile strengths increased as a function of $\mathrm{Zr}$ content. Tensile fracture surfaces were examined by scanning electron microscope and the fractographs reflected the effect of grain structure on the fracture behavior of studied alloys. All fracture surfaces indicated typical dimple ruptures, however, the size of dimples were observed as finer structures as a function of $\mathrm{Zr}$ content. As seen in cross-sectional graphs, as the $\mathrm{Zr}$ content increased the grain structure was refined due to $\mathrm{Al}_{3} \mathrm{Zr}$ precipitates. These fine precipitates caused the formation of fine and shallow dimples under loading.
\end{abstract}

\section{Introduction}

Zirconium is added to aluminum alloys for the following purposes; (i) altering recrystallization behavior, (ii) enhancing mechanical properties and thermal stability while retaining electrical conductivity and (iii) controlling the grain size during solidification. In the first two cases, super saturation of the Al solid solution is achieved during solidification and the metastable $\mathrm{Al}_{3} \mathrm{Zr}$ phase precipitates during annealing, pinning dislocations and subgrain boundaries. In the last case, primary crystals of the equilibrium $\mathrm{Al}_{3} \mathrm{Zr}$ phase act as nucleating substrates for $\mathrm{Al}$ grains [1-2].

In aluminium industry, extrusion is a relatively low expensive process among the manufacturing methods producing profiles with complex shapes and high geometric tolerances in long lengths. Extruded parts are widely used in many areas including transportation for aerospace, automotive and marine applications, several constructions and electronics. In these applications, heat treatable Al-Mg-Si alloys are widely used due to their excellent extrudability and the mechanical requirements of these parts can be achieved by heat treatment procedures [3-4].

\footnotetext{
*Corresponding author: fulya.kahriman@ kocaeli.edu.tr
} 


\section{Experimental study}

The alloys were cast by direct chill (DC) casting in the form of $2 \mathrm{~m}$ long billets with a diameter of $152 \mathrm{~mm}$. The alloying element of zirconium was added using Al-\%10Zr master alloy. The chemical compositions of the alloys are given in Table 1. As-cast billets were homogenized at $580{ }^{\circ} \mathrm{C}$ for 6 hours and subsequently cooled to room temperature.

Table 1. The chemical compositions of the alloys (wt.- $\%$ ).

\begin{tabular}{|c|c|c|c|c|c|c|c|c|}
\hline Alloys & Al & Si & Fe & $\mathbf{C u}$ & $\mathbf{M n}$ & $\mathbf{M g}$ & $\mathbf{T i}$ & $\mathbf{Z r}$ \\
\hline $\mathbf{1}$ & Bal. & 0,870 & 0,277 & 0,007 & 0,639 & 0,835 & 0,012 & 0,025 \\
\hline $\mathbf{2}$ & Bal. & 0,857 & 0,215 & 0,022 & 0,455 & 0,835 & 0,013 & 0,136 \\
\hline $\mathbf{3}$ & Bal. & 0,838 & 0,277 & 0,029 & 0,476 & 0,793 & 0,010 & 0,231 \\
\hline
\end{tabular}

And then, extrusion billets of $350 \mathrm{~mm}$ length were cut from the ingots and extruded by direct extrusion method. After extrusion, samples were taken for metallography. Samples were ground with $\mathrm{SiC}$ papers $(320,600,1000$ and 2500 grit size), polished with $3 \mu \mathrm{m}$ and 1 $\mu \mathrm{m}$ diamond suspensions and examined under optical microscope with polarized light contrast to evaluate grain structure. The microstructures of the alloys were examined using Nikon Eclipse L150A light microscope (LM) and Jeol JSM-6060 scanning electron microscope (SEM). SEM-EDX analyses were carried out to identify the intermetallic phases and for fractographic investigations. Tensile specimens were prepared according to the DIN EN 10002-1 standard and tensile tests were performed by Zwick / Roell Z250 tensile testing machine at room temperature.

\section{Results and Discussion}

\subsection{Microstructural investigation}

Figure 1 presents the microstructures of the investigated alloys in as-cast and homogenized conditions. Alloy 1 shows a typical as-cast microstructure including coarse grains of the $\alpha$-Al dendrites and several precipitates in the interdendritic regions. It can be observed that dendritic structure of the Alloy 2 and Alloy 3 was refined compared with that Alloy 1 by $\mathrm{Zr}$ addition. Besides the dendritic structure has transformed into a equiaxed structure and the intermetallic compounds in the interdendritic regions are distributed finer in the structure. This is in agreement with some of the literature concluding that even minor $\mathrm{Zr}$ addition has considerable effect on the microstructure refinement of aluminium alloys due to presence of Zr-bearing precipitates [5-13]. As seen in the microstructures of the homogenized alloys, the coarse secondary phase particles in the interdenritic regions are dissolved by homogenization to provide a more homogeneous distribution to the structure. In addition, the $\mathrm{Mg}_{2} \mathrm{Si}$ particles dissolve and distribute more spherically morphologically and homogeneously to the structure. The homogenization process also removes microsegregation between the secondary dendrite arms or within the grain [14]. In the SEM-EDX analyzes, intermetallic phases were found to be the well-known rod-like shaped eutectic $\mathrm{Mg}_{2} \mathrm{Si}$, skeleton shaped $\alpha-\mathrm{AlFeMnSi}$ and needle $\beta-\mathrm{AlFeSi}$. 


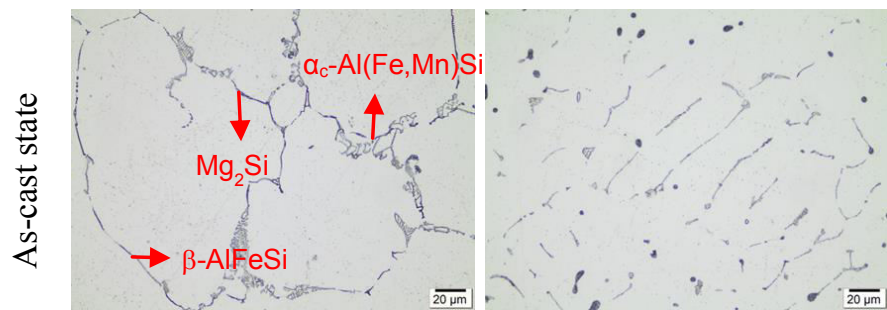

(a)

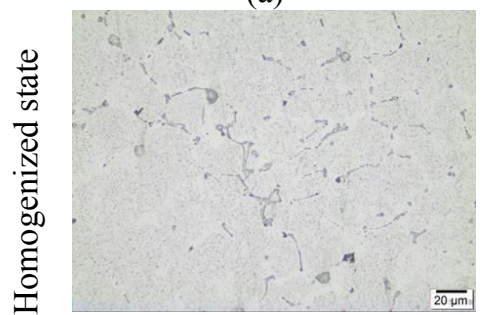

(d) (b)

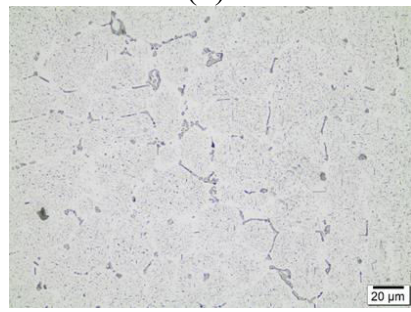

(e)

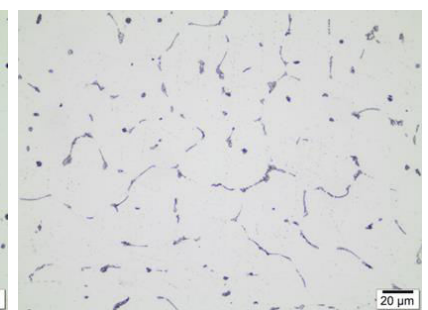

(c)

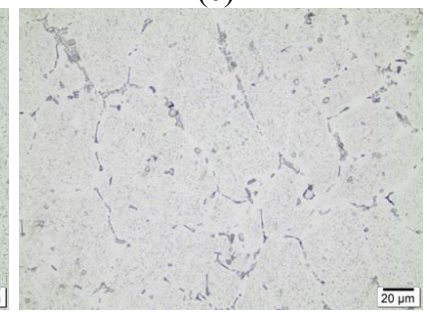

(f)

Fig.1. LM images of the alloy microstructures in as-cast and homogenized states a, d) Alloy 1, b, e) Alloy 2, c, f) Alloy 3.

Recrystallization occurs due to process conditions at the outer edges of the profile and along the profile periphery during the hot extrusion of the hollow profiles. Porthole extrusion dies are used in hollow profile production in the hot extrusion. The porthole extrusion die consists of two parts consists of a mandrel forming the profile inner diameter and welding chamber section. In addition, there is a space forming the profile outer diameter. In the extrusion process, the heated aluminium alloy billet in container is extruded into the upper die and split into separated metal streams by the bridge under the pressure of dummy block. Then, these two divided metal streams are joined in the welding chamber. So that in the direction parallel to the extrusion direction, the longitudinal weld seams zones along the profile length occur. The number of weld seams in the profile depends on the number of porthole in the die. In the experimental study, the mandrel was composed by 5 portholes thus generating 5 seam welds. Figure 2 shows the weld seams in the profiles during extrusion. The profiles consist of deformation-forming fibers at the center of the cross-section and recrystallized regions at the edges of the crosssection and at the weld seams.
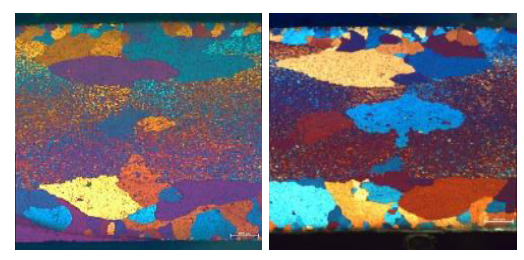

Alloy 1
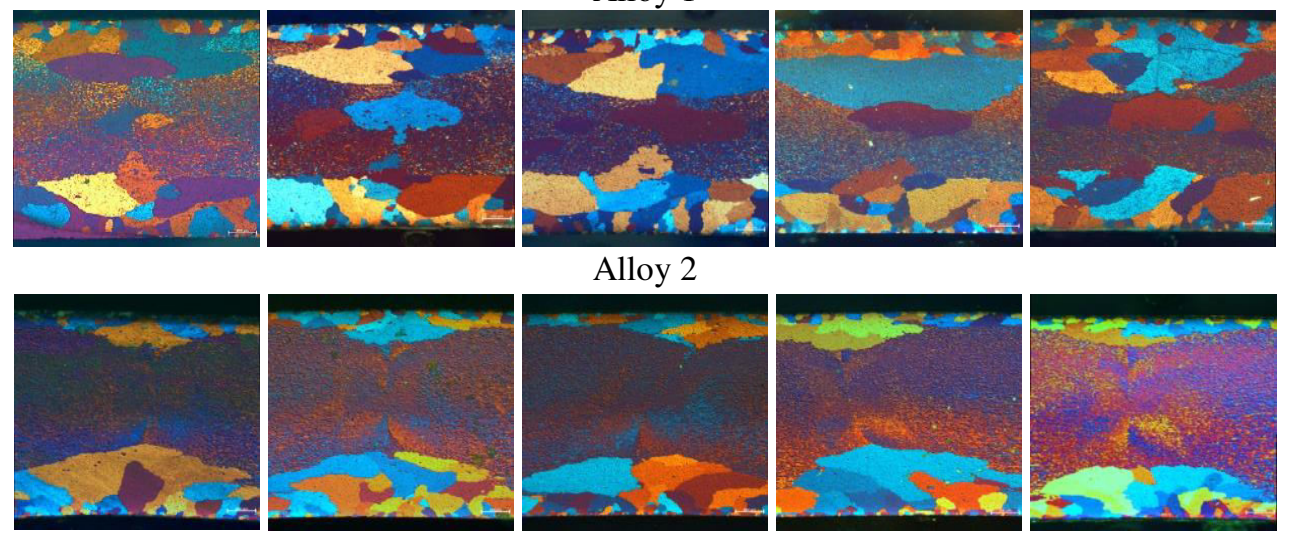

Alloy 2
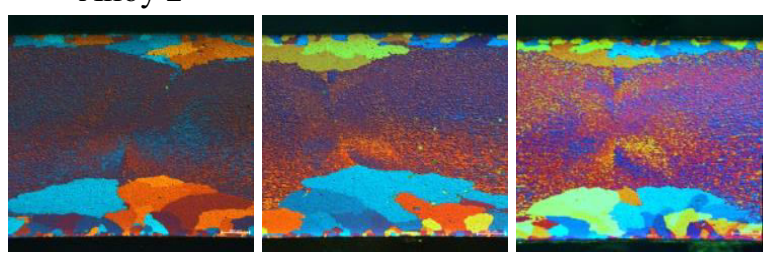

Alloy 3 

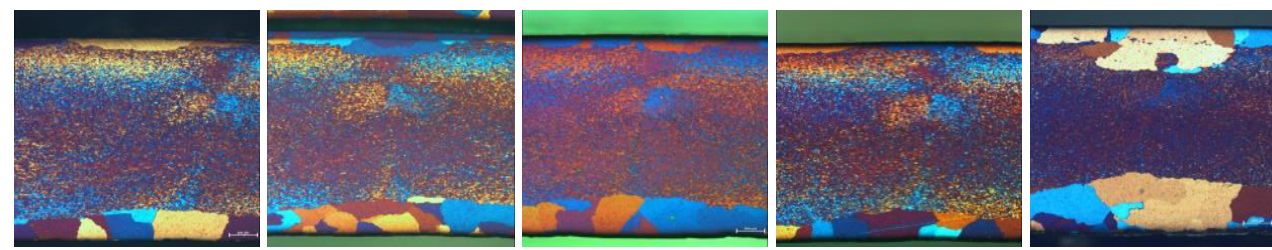

Fig. 2. LM images of extrusion weld seams in profiles.

Zirconium forms fine and metastable $\mathrm{Al}_{3} \mathrm{Zr}$ precipitates in the $\mathrm{L}_{2}$ structure, coherent with the Al matrix, forming during the decomposition of supersaturated solid solution. Their pinning effect can have a huge impact of improving the microstructural properties of aluminium alloys. These precipitates can transform to the equilibrium $\mathrm{D}_{23} \mathrm{Al}_{3} \mathrm{Zr}$ structure during prolonged heat treatment. In 6xxx aluminium alloys with high content of $\mathrm{Si}$, the $(\mathrm{Al}, \mathrm{Si})_{3} \mathrm{Zr}$ precipitate which has $\mathrm{D}_{22}$ structure is formed in place of the equilibrium $\mathrm{D}_{23}$ structure through substitution of $\mathrm{Al}$ by $\mathrm{Si}$ [10]. Crystal structure and lattice constants of $\mathrm{Zr}$ bearing precipitates are extremely similar to those of $\alpha-\mathrm{Al}$ matrix, therefore they promote the heterogeneous nucleation during the solidification process of aluminium alloys and refine the grains of the alloys [12].

\subsection{Tensile Properties and Fractography}

Prior the tensile tests, extruded alloys were subjected to solution heat treated at $560{ }^{\circ} \mathrm{C}$ for $3 \mathrm{~h}$, subsequently quenching in water. Then, the profiles were aged at $180{ }^{\circ} \mathrm{C}$ at times which the maximal hardness values determined by the authors' previous kinetic studies were obtained [15]. And then, uniaxial tensile tests were performed on extruded hollow profiles at room temperature. Four specimens taken parallel to the extrusion direction were tested for each alloy. The results of the tensile test are illustrated in Figure 3.

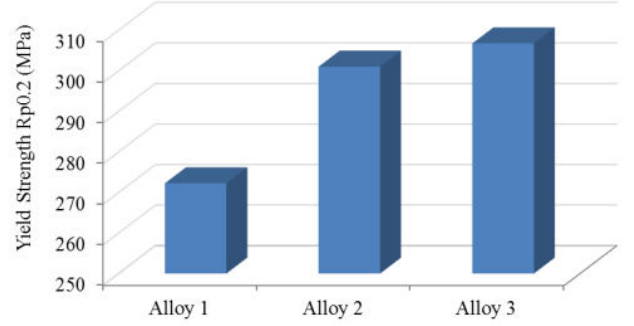

(a)

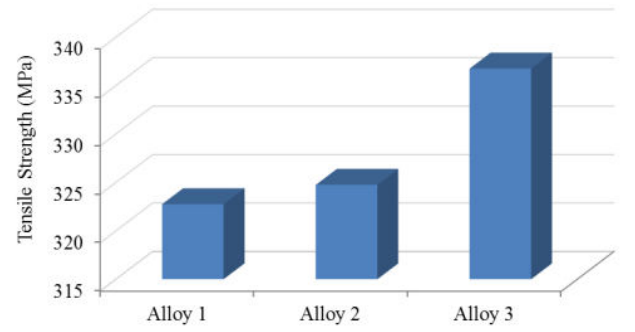

(b) 


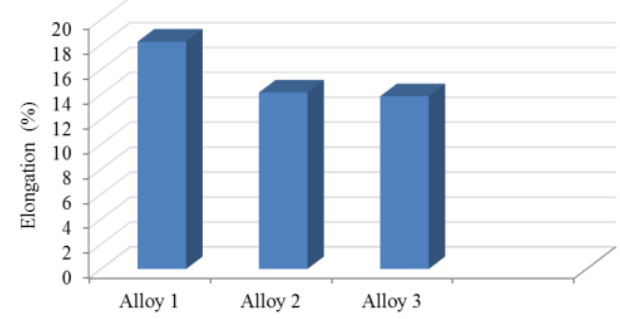

(c)

Fig. 3. The strengths of the profiles; a) variation of yield, b) variation of tensile and c) variation of elongation as a function of $\mathrm{Zr}$ content.

It can be seen that the addition of $\mathrm{Zr}$ improved the yield strength of the extruded alloys from $272 \mathrm{MPa}$ to $307 \mathrm{MPa}$. Besides, the ultimate tensile strength of the alloys increased from $322 \mathrm{MPa}$ to $328 \mathrm{MPa}$, while the elongation decreases slightly from $18 \%$ to $14 \%$. Figure 4 shows the macro images of the fractured surfaces of the tensile specimens. Specimens were broken under uniaxial loading along the direction of maximum shear stress is at $45^{\circ}$ to the loading axis.

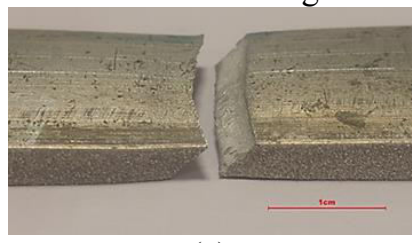

(a)

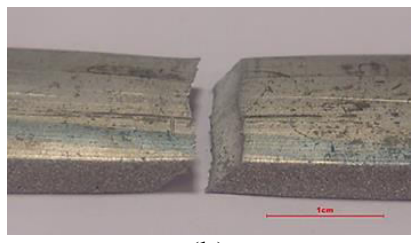

(b)

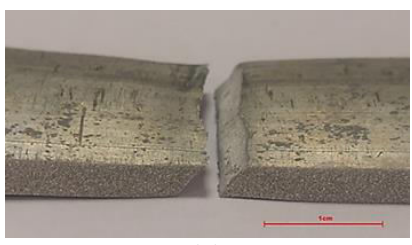

(c)

Fig. 4. Macro images of the fractured surfaces of the a) Alloy 1, b) Alloy 2 and c) Alloy 3.

SEM images of fractured surfaces of the extruded alloys are shown in Figure 5. When the material is overloaded under uniaxial stress state, most of the structural alloys are damaged by a process consist of microvoid nucleation, growth and coalescence. These microvoids nucleate in local strain discontinuities such as secondary phase particles, inclusions, grain boundaries and dislocations. As the stress concentration in the material increase, the micro voids grow, coalesce and finally form a fracture surface. This type of fracture is known as ductile fracture. The Figure 5a demonstrates that the Alloy 1 was failed completely by ductile rupture which has large sized dimples caused by the coarse intermetallic particles and precipitates. However, fracture surfaces of Alloy 2 and Alloy 3 consists of small and shallow dimples. There are almost no dimples, but only quasi-brittle fracture zones along coarse brittle phase particles such as (Al,Si) ${ }_{3} \mathrm{Zr}$ (Figure 5b). Furthermore, there are fine and relatively large dimples in the fracture surfaces of the Alloy 2 and Alloy 3 (Figure 5b and 5c) indicating non-uniform distribution and size of precipitate particles.

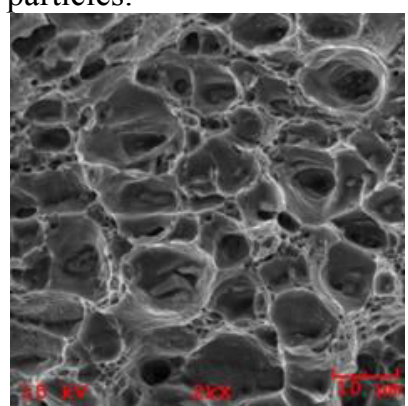

(a)

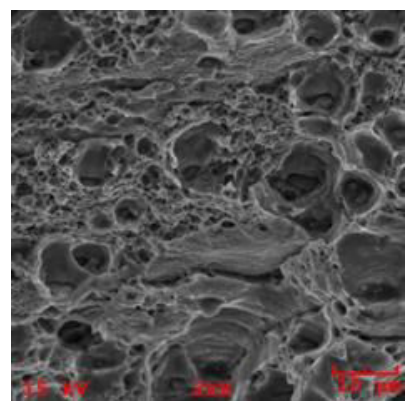

(b)

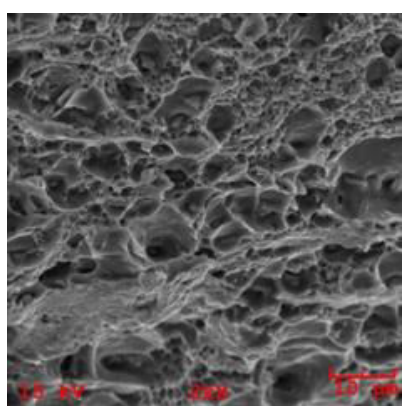

(c) 
Fig. 5. SEM images of the fractured surfaces of the profiles; a) Alloy 1, b) Alloy 2 and c) Alloy 3 .

Also, two structures of the $\mathrm{Zr}$ bearing precipitates mentioned above were found in SEM examinations coupled with EDX analysis, on the fractured surface of Alloy 3 (Figure 6).

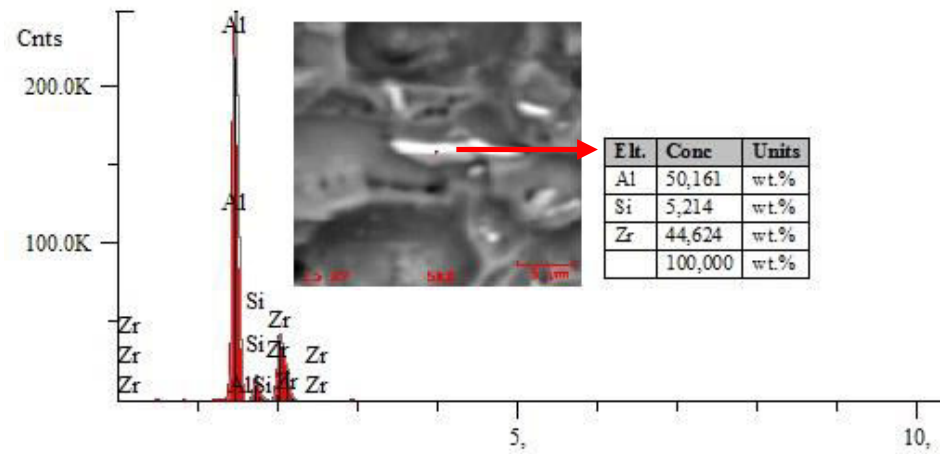

(a)

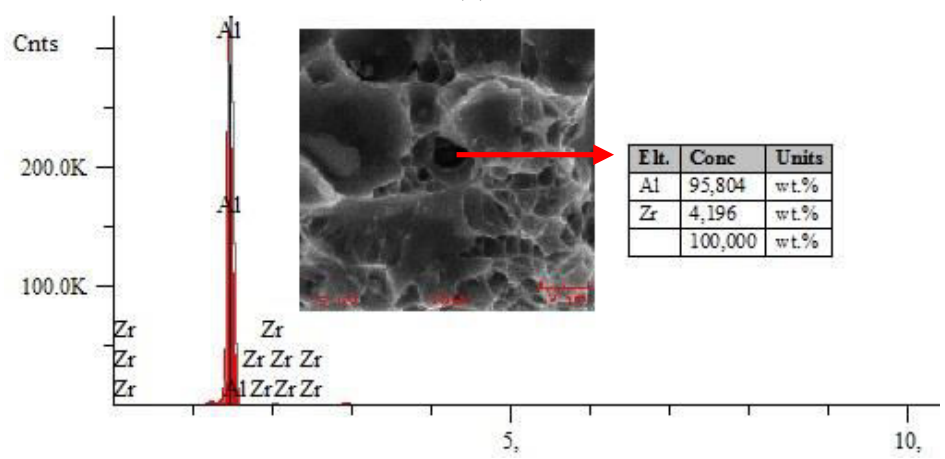

(b)

Fig. 6. SEM/EDX analyses of Zr bearing precipitates on fractured surface of Alloy 3.

\section{Conclusions}

After examining the results of the study, the following conclusions were drawn:

i) $\mathrm{Zr}$ addition results in finer equiaxed dendritic microstructure of the alloys. Because primary $\mathrm{Al}_{3} \mathrm{Zr}$ precipitates act as nuclei to solidify $\alpha-\mathrm{Al}$ and thus promote heterogeneous nucleation.

ii) The addition of $\mathrm{Zr}$ increased the recrystallization resistance of the alloy. Because the energy of interface between the coherent secondary precipitates and the matrix is very low. Because it is difficult to pass these low energy boundaries for grain boundaries, border movements are inhibited. Thus, the thermal stability of the alloy increases and the recrystallization resistance increases.

iii) The ultimate tensile strength and the yield strength of the alloys with the $\mathrm{Zr}$ addition are improved while ductility is still retained. Fractographic examinations of the fractured surfaces of the alloys reveal dimples indicating ductile fracture. With $\mathrm{Zr}$ addition, that is, with reduction in elongation and improvement of yield and ultimate strength, small and 
shallow dimples are apparent. Furthermore, with $\mathrm{Zr}$ addition although the elongation is small, fracture surface shows a mixed morphology with an increased number of dimples that are also small.

The authors gratefully acknowledge the financial support of the Scientific Research Projects Coordination Unit of Kocaeli University (Project number: 2013/072). The authors also thank Onat Profile and Alloy Industry and Trade Ltd. Co. for their assistance in providing the alloys used in the study and carrying out the tensile tests.

\section{References}

1. F. Wang, D.G. Eskin, A.V. Khvan, K.F. Starodub, J.J.H. Lim, M.G. Burke, T. Connolley, J. Mi, Scripta Materialia, 133, $75-78$ (2017).

2. K.T. Kashyap, Bull. Mater. Sci., 24-6, 643-648 (2001).

3. X. Ren, J. L. Zhang, J. P. Li, J. Liu, H. H. Zhang, X. R. Wang, 3rd International Conference on Material, Mechanical and Manufacturing Engineering (IC3ME 2015).

4. O. Reiso, Materials Forum 28, 32-46 (2004).

5. P. Sharma, D. Khanduja, S. Sharma, J Mater Res Technol. (5)1, 29-36 (2016).

6. S. Camero, E.S. Puchi, G. Gonzalez, J Mater Sci. 41, 7361-7373 (2006).

7. K. Venkateswarlu, L.C. Pathak, A.K. Ray, G. Das, P.K. Verma, M. Kumar, R.N. Ghosh, Materials Science and Engineering: A, 383(2), 374-380 (2004).

8. Z. H.Jia, H.L. Huang, X.L. Wang, Y. Xing, Q. Liu, Acta Metall. Sin. (Engl. Lett.) 29(2), 105-119 (2016).

9. Y. Meng, Z. Zhao, J.Cui, Trans. Nonferrous Met. Soc. China 23, 1882-1889 (2013).

10. L. Lityñska, D.Abou-ras, G. Kostorz, J. Dutkiewicz, Journal of Microscopy 223, 182-184 (2006).

11. E. Cerri, P. Leo, Metal Science and Engineering A 410-411, 226-229 (2005).

12. X. Qingchun, Z. Jing, P. Haicheng, H. Lina, L. Rongde, China Foundry 8(1), 137-140 (2011).

13. M. Cabibbo, E. Evangelista, J Mater Sci 41(16), 5329-5338 (2006).

14. G. Mrówka-Nowotnik, J. Sieniawski, Journal of Materials Processing Technology 162-163, 367-372 (2005).

15. F. Kahriman, M. Zeren, International Journal of Metalcasting, Volume 11, Issue 2, doi: 10.1007/s40962-016-0047-1, 216-222 (2017). 